\title{
BMJ Open Caesarean section and the association with migraine: a retrospective register- linked HUNT population cohort study
}

Espen Saxhaug Kristoffersen (1) , 1,2,3 Sigrid Børte, ${ }^{2,4}$ Knut Hagen, 5,6 John-Anker Zwart, ${ }^{2,4,7}$ Bendik Slagsvold Winsvold ${ }^{2,7}$

To cite: Kristoffersen ES, Børte S, Hagen K, et al. Caesarean section and the association with migraine: a retrospective registerlinked HUNT population cohort study. BMJ Open 2020;10:e040685. doi:10.1136/ bmjopen-2020-040685

- Prepublication history for this paper is available online. To view these files, please visit the journal online (http://dx.doi. org/10.1136/bmjopen-2020040685).

Received 20 May 2020

Revised 05 September 2020

Accepted 23 October 2020

A) Check for updates

(C) Author(s) (or their employer(s)) 2020. Re-use permitted under CC BY-NC. No commercial re-use. See rights and permissions. Published by BMJ.

For numbered affiliations see end of article.

\section{Correspondence to} Espen Saxhaug Kristoffersen; e.s.kristoffersen@medisin. uio.no

\section{ABSTRACT}

Objectives To evaluate the association between caesarean section and migraine in a population-based register-linked cohort study.

Setting Data from the population-based Nord-Trøndelag Health Studies (HUNT2 and HUNT3) were linked to information from the Norwegian Medical Birth Registry. Participants 65343 participants responded to the headache questions in any of the two HUNT studies. Only those answering the headache questions in HUNT2 or 3 and had information about mode of delivery in the Norwegian Medical Birth Registry (born after 1967) were included. Our final sample consisted of 6592 women and 4602 men, aged $19-41$ years.

Outcomes ORs for migraine given caesarean section. Analyses were performed in multivariate logistic regression models.

Results After adjusting for sex, age and fetal growth restriction, delivery by caesarean section was not associated with migraine later in life (OR $0.86,95 \% \mathrm{Cl} 0.64$ to 1.15). Delivery by caesarean section was associated with a reduced $\mathrm{OR}$ of non-migrainous headache (OR 0.77 , $95 \% \mathrm{Cl} 0.60$ to 0.99 ).

Conclusion No association was found between caesarean section and migraine in this population-based registerlinked study.

\section{INTRODUCTION}

The increasing use of caesarean section throughout the Western world has led to concerns about possible short-term and longterm consequences for the newborn child. ${ }^{1-3}$

Reported short-term negative health effects during the neonatal period include impaired lung function, hypoglycaemia, reduced breastfeeding initiation and altered innate and adaptive immune responses. ${ }^{2}$ In the long term, caesarean section has been linked to increased risk of diabetes mellitus type I and II, arthritis, dyslipidaemia, metabolic syndrome, obesity, coeliac disease and inflammatory bowel disease, and a recent study reported an increased risk of chronic inflammatory disorders at least 40 years after caesarean delivery. ${ }^{4-9}$ Unlike those born vaginally, children delivered by caesarean section

\section{Strengths and limitations of this study}

Sample from the general population.

- Linkage through the unique personal identification number to the National Medical Birth Registry.

- Validated headache questionnaires based on the International Classification of Headache Disorders.

- Large separation in time between mode of delivery at birth and development of later migraine.

- Lack of more detailed information from the Medical Birth Registry.

are not exposed to maternal vaginal and faecal bacteria at birth, but rather to skin bacteria. It has been suggested that this results in altered bacterial communities and microbiota, ${ }^{10-12}$ which in turn can lead to an increased response to environmental factors, predisposing to autoimmunity and chronic inflammatory disorders later in life. ${ }^{10-12}$ As the brain and the gastrointestinal tract are strongly connected via neural, humoral and immune pathways, there is an increasing interest in the gut-brain connection within the neuroscience field. ${ }^{12-14}$ Migraine is a common chronic neurological disorder usually starting during early adulthood, but may also be present from childhood. ${ }^{15}$ The exact mechanism behind migraine is unknown, but both genetic and environmental factors are involved. ${ }^{15}$ It has been associated with several immunemediated conditions including asthma, allergic rhinitis, allergic conjunctivitis, atopic disease, coeliac disease, inflammatory bowel diseases, systemic lupus erythematosus and Sjögren's syndrome. ${ }^{16-19}$

The possible role of mode of delivery has not been examined in prior studies of migraine. We hypothesised that caesarean section increases the risk of migraine and our aim was to explore the association between being delivered by caesarean section and migraine later in life. 


\section{METHODS}

\section{Study population}

The Nord-Trøndelag Health Study (HUNT) is a large, population-based cohort study carried out in NordTrøndelag county, Norway. The study has been described in detail elsewhere. ${ }^{20}$ Briefly, in HUNT2 (1995-1997) and HUNT3 (2006-2008), all inhabitants (age $\geq 20$ ) in the county were invited to participate. Data were collected using questionnaires, including more than 200 health-related questions, and clinical examinations. We combined the HUNT2 and HUNT3 Surveys and used them in a retrospective cohort study design.

Information on mode of delivery was obtained through the Norwegian Medical Birth Registry. ${ }^{21}$ The Norwegian Medical Birth Registry contains data on all live births and stillbirths in Norway since 1967, including: date of birth, birth weight, birth length, single or multiple birth, gestational age, malformations and mode of delivery (vaginal birth or caesarean section). The data are reported by the attending health personnel shortly after birth. These data are used to produce the official birth statistics, including counts of caesarean section deliveries. ${ }^{21}{ }^{22}$ Additional information, such as specific diagnoses in the newborn, complications during pregnancy or labour, maternal smoking, alcohol use, medical conditions and medication use, were incomplete in the forms used before 1999 and were therefore not included.

Data were linked to HUNT by the use of the Norwegian personal identification numbers that are unique for each citizen.

Since some individuals participated in more than one survey, HUNT2 was chosen as the default dataset. We then added individuals from HUNT3 if the individual had not participated in HUNT2. In total, 65343 participants responded to the headache questions in any of the two HUNT studies (figure 1). Among those answering the headache questions, 12681 were born in 1967 or later, and of these 12289, 97\% had information about mode of delivery in the Norwegian Medical Birth Registry. We

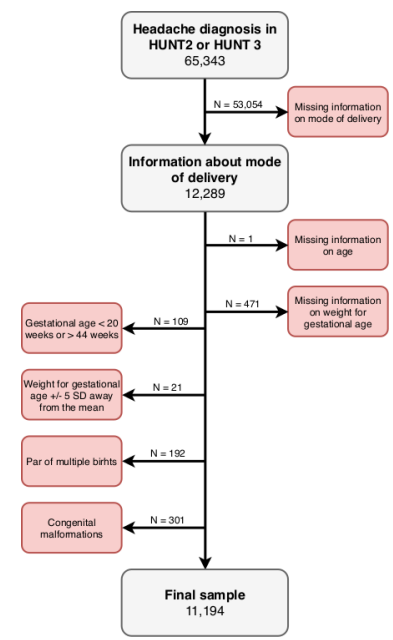

Figure 1 Flowchart shows selection of participants. HUNT, Nord-Trøndelag Health Study. excluded those with missing information on age $(n=1)$ or weight for gestational age $(n=471)$. Furthermore, we excluded pregnancies with specific factors giving high risk for both caesarean section and complications, where the relation to migraine is not known: those who were born $<20$ weeks of gestation or $>44$ weeks $(n=109)$, had weight for gestational age $>5$ SD away from the Scandinavian reference mean $(n=21)$, were part of multiple births $(n=192)$ or had congenital malformations $(n=301)$. This resulted in a final sample of 11194 participants.

\section{Headache diagnoses}

Headache diagnoses were assessed using questionnaires and classified as migraine or non-migrainous headache based on a modified version of the International Classification of Headache Disorders (ICHD-II). ${ }^{23}$ Subjects who answered 'yes' to the question 'Have you suffered from headache during the last 12 months?' were classified as active headache sufferers. Those who answered 'no' constitute the headache-free group. Based on the subsequent headache questions, headache sufferers were classified as having migraine if they fulfilled the following three criteria: (1) headache attacks lasting 4-72 hours, ( $<4$ hours was accepted for those who reported commonly occurring visual disturbances before headache); (2) headache with at least one of the following characteristics: pulsating quality, unilateral location or aggravation by physical activity and (3) during headache, at least one of the following occurred: nausea, photophobia and phonophobia. In addition, the participants were asked if they suffered from migraine; those who responded positively to this question were also included in the migraine group. Headache sufferers who did not fulfil the criteria for migraine were classified as having non-migrainous headache, and the diagnoses were mutually exclusive. The migraine diagnosis has previously been validated by clinical interviews performed by neurologists. In HUNT2, the sensitivity was $69 \%$ and specificity $89 \% \quad(\kappa=0.59,95 \%$ CI 0.47 to 0.71$).{ }^{24}$ In HUNT3, the sensitivity and specificity were $49 \%$ and $96 \%$, respectively, $(\kappa=0.51,95 \%$ CI 0.34 to $0.68){ }^{25}$

\section{Mode of delivery \\ Mode of delivery was divided into vaginal birth or caesarean section based on information from the Norwe- gian Medical Birth Registry.}

\section{Covariates}

Identification of potential confounding factors was based on a priori knowledge of possible risk factors for caesarian section or migraine and modelled with a directed acyclic graph (DAG) to visualise causal assumptions (figure 2). The variables considered to be potential confounders from the DAG, and possible to assess in our data were sex, age and foetal growth restriction. Certain other potential confounders, including maternal migraine, body mass index (BMI) and smoking, could not be examined as they were not consistently registered in the Norwegian 


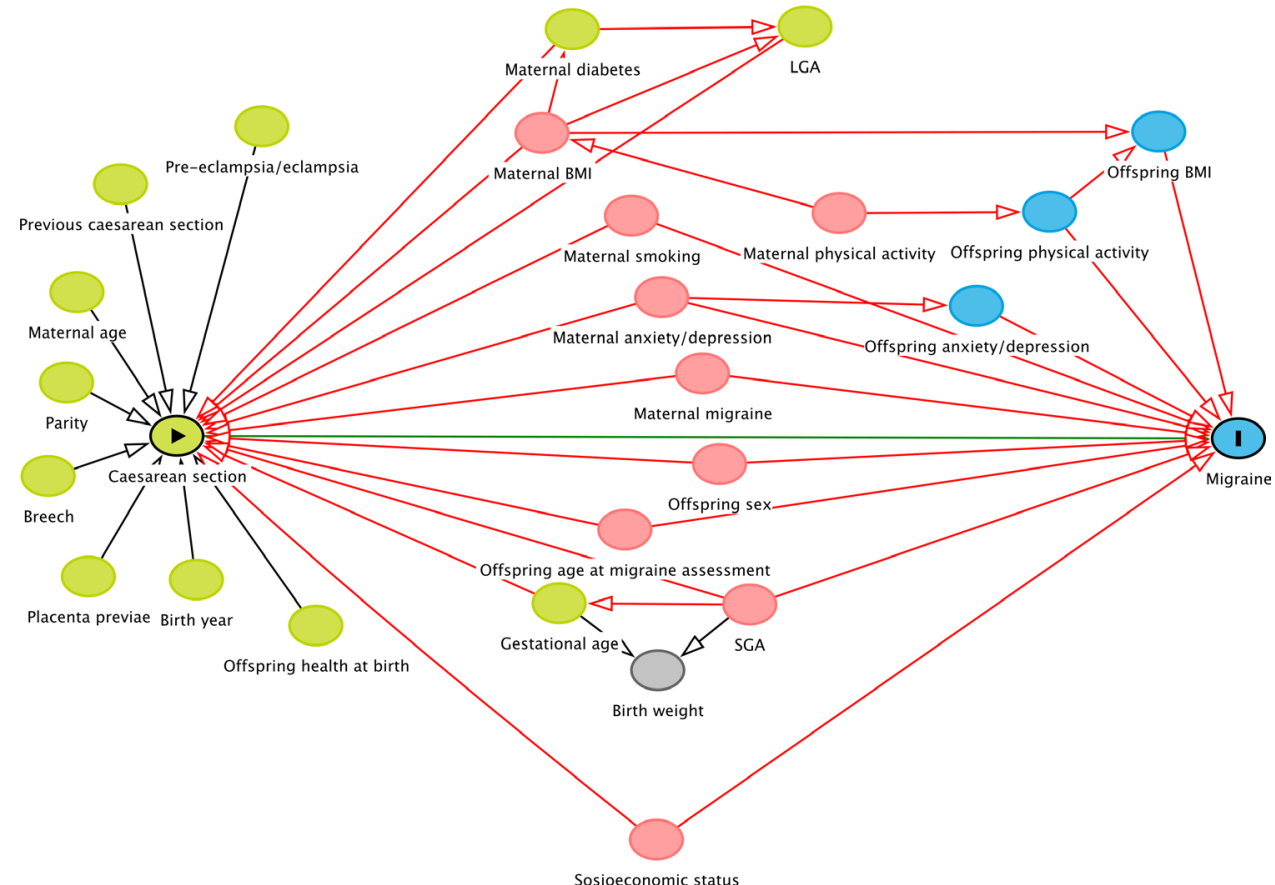

Figure 2 A directed acyclic graph of the model of potential confounding factors. BMI; body mass index, LGA; large for gestational age, SGA; small for gestational age.

Medical Birth Registry prior to 1999. Age was categorised into 5-year groups, since it was not linearly associated with migraine on the logit scale. Foetal growth restriction was defined as birth weight by gestational age and sex below the 10 th percentile. As a reference, we used those who were not born growth restricted (ie, birth weight by gestational age and sex $\geq 10$ th percentile). To calculate the percentiles, we standardised birth weight according to gestational age and sex based on national reference data and expressed them as z-scores. ${ }^{26}$

\section{Data analysis}

All analyses were performed using logistic regression models. We estimated ORs and 95\% CIs for the association between caesarean section (exposure) and migraine or non-migrainous headache (outcome), using headachefree participants as controls. Two-tailed $\mathrm{p}$ values are reported, using 0.05 as a cut-off value for statistical significance. Statistical analyses were performed using Stata/
SE V.15.1 for Mac (StataCorp LP, College Station, Texas, USA).

\section{RESULTS}

Our final sample consisted of 11194 individuals, with a mean age of 27.2 years (range 19.0-41.4 years). Of these, $1855(16.6 \%)$ had migraine and $3358(30.0 \%)$ had nonmigrainous headache. In total, 367 individuals (3.3\%) were born by caesarean section, and 10827 (96.7\%) were born vaginally. Characteristics of the participants are presented in table 1. Compared with headache-free controls participants with migraine and non-migrainous headache were more likely women, slightly older and included a higher proportion of individuals born growth restricted. In addition, those with non-migrainous headache had a lower prevalence of caesarean section than headache-free controls.

Table 1 Characteristics of the participants

\begin{tabular}{llll}
\hline & $\begin{array}{l}\text { No headache } \\
\mathbf{N}=5981\end{array}$ & $\begin{array}{l}\text { Migraine } \\
\mathbf{N = 1 8 5 5}\end{array}$ & $\begin{array}{l}\text { Non-migrainous headache } \\
\mathbf{N}=3358\end{array}$ \\
\hline Sex, female, \% (n) & $48.9(2924)$ & $77.0(1429)^{\star \star}$ & $66.7(2239)^{\star \star}$ \\
Age, mean years (SD) & $26.9(0.07)$ & $28.1(0.13)^{\star \star \star}$ & $27.5(0.10)^{\star \star \star}$ \\
Foetal growth restriction, \% (n) & $10.9(653)$ & $13.2(244)^{\star \star}$ & $12.3(414)^{\star}$ \\
Caesarean section, \% (n) & $3.6(217)$ & $3.1(58)$ & $2.7(92)^{\star}$
\end{tabular}

Group mean or proportion is significantly different from no-headache control mean or proportion at ${ }^{*} \mathrm{p}<0.05$, ${ }^{* *} \mathrm{p}<0.01$ and ${ }^{* \star *} \mathrm{p}<0.001$ as determined by $\chi^{2}$ tests for categorical variables and independent $t$-tests for continuous variables. 
Table 2 The association between caesarean section on development of migraine

\begin{tabular}{|c|c|c|c|c|c|c|c|}
\hline & \multirow[b]{3}{*}{$\mathbf{N}$} & \multicolumn{6}{|c|}{ Migraine } \\
\hline & & \multicolumn{2}{|l|}{ Crude } & \multirow[b]{2}{*}{$P$ value } & \multicolumn{2}{|c|}{ Adjusted $^{*}$} & \multirow[b]{2}{*}{$P$ value } \\
\hline & & OR & $95 \% \mathrm{Cl}$ & & OR & $95 \% \mathrm{Cl}$ & \\
\hline \multicolumn{8}{|l|}{ Mode of delivery } \\
\hline Vaginal delivery & 7561 & 1 & & & 1 & & \\
\hline Caesarean section & 275 & 0.86 & 0.64 to 1.15 & 0.31 & 0.93 & 0.68 to 1.26 & 0.63 \\
\hline
\end{tabular}

${ }^{*}$ The analysis was adjusted for offspring age, sex and foetal growth restriction.

For migraine, there was no association between being delivered by caesarean section and later development of migraine, neither in the crude (OR $0.86,95 \%$ CI 0.64 to $1.15, \mathrm{p}=0.31$ ) or adjusted models (OR $0.93,95 \%$ CI 0.68 to $1.26, \mathrm{p}=0.63$ ) (table 2).

For non-migrainous headache, we found a negative association with caesarean section, both in the crude (OR $0.75,95 \%$ CI 0.58 to $0.96, \mathrm{p}=0.02$ ) and the adjusted (OR $0.77,95 \%$ CI 0.60 to $0.99, \mathrm{p}=0.04$ ) models (table 3 ).

\section{DISCUSSION}

In this large population-based registry-linked study, we found that mode of delivery at birth was not associated with migraine in adulthood. Caesarean section was, however, associated with a modestly reduced odds of having non-migrainous headache, compared with those born vaginally.

There is generally little knowledge about how factors early in life affect the development of migraine, ${ }^{27}$ and to the best of our knowledge, no previous studies have investigated the effect of mode of delivery.

Migraine usually starts during childhood or early adulthood and several lines of evidence implicate the immune system in migraine pathogenesis. ${ }^{14}{ }^{15} 28-30$ It has been suggested that increased rates of caesarean section are partly responsible for the increasing incidence of certain autoimmune diseases, including inflammatory bowel diseases, coeliac disease, asthma and rheumatoid arthritis, although results are conflicting. ${ }^{8} 931-34$ While several of these conditions are typically present during childhood, conditions usually developing in adulthood have also been found to be associated with caesarean delivery. ${ }^{459}$ Norway has a relatively low caesarean section rate compared with many other European countries, but rates have steadily increased from less than 2\% in 1967 to $16.1 \%$ in $2018 .{ }^{21}$ At the same time, there has been an increasing prevalence of migraine among adolescents both in Norway and other countries. ${ }^{35} 36$

Our study does, however, suggest that mode of delivery is likely not of major importance for the later development of migraine.

The finding that caesarean section was associated with a modestly reduced odds of having non-migraine headache in adult life is difficult to interpret into pathophysiological or clinical relevance, since the group is heterogenous and will include a variety of headache disorders. If further studies are conducted, this suggests that they should also include headache disorders other than migraine.

Strengths of this study include the use of a large and unselected population-based sample, linked to the National Medical Birth Registry, which should be a representative for the Norwegian population. ${ }^{21} 22$ The general health focus of the questionnaires decreases the risk of a specific selection bias in relation to headache diagnoses. The migraine diagnoses were validated and based on the ICHD criteria. Although HUNT2 and HUNT3 used ICHD-II, the migraine criteria did not change to the present ICHD-3. ${ }^{23}{ }^{37}$ The use of questionnaire-based headache diagnoses rather than clinical interview will lead to a degree of misclassification for headache status. We believe this misclassification is non-differential, since mode of delivery is unlikely to affect the risk of headache misclassification, and it would be expected to lead to an underestimation of the effect, thus reducing our power to detect a true effect.

A limitation of the study is the lack of more detailed information from the Medical Birth Registry. In our data, we could not distinguish between emergency

Table 3 The association between caesarean section on development of non-migrainous headache

\begin{tabular}{|c|c|c|c|c|c|c|c|}
\hline & \multirow[b]{3}{*}{$\mathbf{N}$} & \multicolumn{6}{|c|}{ Non-migrainous headache } \\
\hline & & Crude & & & Adjusted* & & \\
\hline & & OR & $95 \% \mathrm{Cl}$ & $P$ value & OR & $95 \% \mathrm{Cl}$ & $P$ value \\
\hline Vaginal delivery & 9030 & 1 & & & 1 & & \\
\hline Caesarean section & 309 & 0.75 & 0.58 to 0.96 & 0.02 & 0.77 & 0.60 to 0.99 & 0.04 \\
\hline
\end{tabular}

${ }^{*}$ The adjusted analyses included offspring age, sex and foetal growth restriction in the model. 
versus elective caesarean section, which may have been of importance. While newborns delivered by elective caesarean section do not acquire bacteria from the birth canal, those delivered by emergency caesarean section are usually in contact with the microbial environment of the birth canal. In addition, we are missing information about parental migraine. We know that migraine tends to run in families, and that parental migraine is associated with increased risk of offspring migraine. ${ }^{38}$ However, whether maternal migraine affects the mode of delivery has not been investigated yet. Maternal age is known to be associated with caesarean delivery rates but is probably less relevant for the development of migraine in the offspring. Both socioeconomic status, low physical activity, obesity and high psychological distress, in mothers increase the risk of caesarean delivery and migraine,${ }^{1-3} 39-41$ but this information is not available in our data. However, confounding by these factors would be expected to bias results towards a positive association, making it unlikely that unmeasured confounding from these factors can explain the lack of an association between caesarean section and migraine. Lastly, the large separation in time between mode of delivery at birth and migraine, typically presenting decades later, makes it challenging to study their potential association in a retrospective study. However, this challenge is somewhat limited by the use of a representative population sample combined with near complete retrospective information on mode of delivery.

In conclusion, we found no association between being born by caesarean section and migraine in adulthood. We suggest that genetic and environmental factors other than mode of delivery are more likely to be responsible for the potential relationship between the microbiome, gut and the development of migraine.

\section{Key findings}

There was no association between being born by caesarean section and later migraine. Genetic and environmental factors other than mode of delivery are more likely to be responsible for the potential relationship between the microbiome, gut and the development of migraine.

\section{Author affiliations \\ ${ }^{1}$ Department of General Practice, Institute of Health and Society, University of Oslo, Oslo, Norway \\ ${ }^{2}$ Research and Communication Unit for Musculoskeletal Health, Division of Clinical Neuroscience, Oslo University Hospital, Oslo, Norway \\ ${ }^{3}$ Department of Neurology, Akershus University Hospital, Lørenskog, Norway \\ ${ }^{4}$ Institute of Clinical Medicine, University of Oslo, Oslo, Norway \\ ${ }^{5}$ Department of Neuromedicine and Movement science, Norwegian University of Science and Technology, Trondheim, Norway \\ ${ }^{6}$ Clinical Research Unit Central Norway, St. Olavs University Hospital, Trondheim, Norway \\ ${ }^{7}$ Department of Research, Innovation and Education, Division of Clinical Neuroscience, Oslo University Hospital, Oslo, Norway}

Acknowledgements The Nord-Trøndelag Health Study (HUNT Study) is a collaboration between HUNT Research Centre (Faculty of Medicine and Health Sciences, NTNU, Norwegian University of Science and Technology), Trøndelag County Council, Central Norway Health Authority and the Norwegian Institute of Public Health.
Contributors ESK had the original idea for the study and together with BSW, SB and J-AZ planned the overall design. ESK prepared the initial draft and was the main author of the present manuscript. SB conducted the data analyses. All authors planned the statistics methodology and were involved in all analyses. All authors have read, revised and approved the final manuscript.

Funding This study is supported by grants from the University of 0slo, Akershus University Hospital and Oslo University Hospital. The funding sources had no role in the design of the study; the collection, analysis and interpretation of the data; preparation of the manuscript or the decision to submit the manuscript for publication.

\section{Competing interests None declared.}

Patient and public involvement Patients and/or the public were not involved in the design, or conduct, or reporting, or dissemination plans of this research.

Patient consent for publication Not required.

Ethics approval Participation was based on informed, written consent, and the study was approved by the Regional Committee for Medical and Health Research (2013/1077/REK sør-øst). In addition, the HUNT Study was approved by the Norwegian Data Inspectorate.

Provenance and peer review Not commissioned; externally peer reviewed.

Data availability statement No data are available. The authors declare that the data supporting the findings of this study are available within the article.

Open access This is an open access article distributed in accordance with the Creative Commons Attribution Non Commercial (CC BY-NC 4.0) license, which permits others to distribute, remix, adapt, build upon this work non-commercially, and license their derivative works on different terms, provided the original work is properly cited, appropriate credit is given, any changes made indicated, and the use is non-commercial. See: http://creativecommons.org/licenses/by-nc/4.0/.

\section{ORCID iD}

Espen Saxhaug Kristoffersen http://orcid.org/0000-0002-8999-5424

\section{REFERENCES}

1 Boerma T, Ronsmans C, Melesse DY, et al. Global epidemiology of use of and disparities in caesarean sections. Lancet 2018;392:1341-8.

2 Sandall J, Tribe RM, Avery L, et al. Short-Term and long-term effects of caesarean section on the health of women and children. Lancet 2018;392:1349-57.

3 Black M, Bhattacharya S, Philip S, et al. Planned cesarean delivery at term and adverse outcomes in childhood health. JAMA 2015;314:2271-9.

4 Darmasseelane K, Hyde MJ, Santhakumaran S, et al. Mode of delivery and offspring body mass index, overweight and obesity in adult life: a systematic review and meta-analysis. PLoS One 2014;9:e87896.

5 Hansen S, Halldorsson TI, Olsen SF, et al. Birth by cesarean section in relation to adult offspring overweight and biomarkers of cardiometabolic risk. Int J Obes 2018;42:15-19.

6 Chavarro JE, Martín-Calvo N, Yuan C, et al. Association of birth by cesarean delivery with obesity and type 2 diabetes among adult women. JAMA Netw Open 2020;3:e202605.

7 Mårild K, Stephansson O, Montgomery S, et al. Pregnancy outcome and risk of celiac disease in offspring: a nationwide case-control study. Gastroenterology 2012;142:39-45.

8 Sevelsted A, Stokholm J, Bønnelykke K, et al. Cesarean section and chronic immune disorders. Pediatrics 2015;135:e92-8.

9 Andersen V, Möller S, Jensen PB, et al. Caesarean delivery and risk of chronic inflammatory diseases (inflammatory bowel disease, rheumatoid arthritis, coeliac disease, and diabetes mellitus): a population based registry study of $2,699,479$ births in Denmark during 1973-2016. Clin Epidemiol 2020;12:287-93.

10 Francino MP. Birth Mode-Related differences in gut microbiota colonization and immune system development. Ann Nutr Metab 2018;73 Suppl 3:12-16.

11 Wampach L, Heintz-Buschart A, Fritz JV, et al. Birth mode is associated with earliest strain-conferred gut microbiome functions and immunostimulatory potential. Nat Commun 2018;9:5091.

12 Heiss CN, Olofsson LE. The role of the gut microbiota in development, function and disorders of the central nervous system and the enteric nervous system. J Neuroendocrinol 2019;31:e12684. 
13 Ma Q, Xing C, Long W, et al. Impact of microbiota on central nervous system and neurological diseases: the gut-brain axis. $J$ Neuroinflammation 2019;16:53.

14 Arzani M, Jahromi SR, Ghorbani Z, et al. Gut-Brain axis and migraine headache: a comprehensive review. J Headache Pain 2020;21:15.

15 Vetvik KG, MacGregor EA. Sex differences in the epidemiology, clinical features, and pathophysiology of migraine. Lancet Neuro 2017;16:76-87.

16 Wang I-C, Tsai J-D, Lin C-L, et al. Allergic rhinitis and associated risk of migraine among children: a nationwide population-based cohort study. Int Forum Allergy Rhinol 2016;6:322-7.

17 Wang I-C, Tsai J-D, Shen T-C, et al. Allergic conjunctivitis and the associated risk of migraine among children: a nationwide populationbased cohort study. Ocul Immunol Inflamm 2017;25:802-10.

18 Le Gal J, Michel JF, Rinaldi VE, et al. Association between functional gastrointestinal disorders and migraine in children and adolescents: a case-control study. Lancet Gastroenterol Hepatol 2016;1:114-21.

19 Tjensvoll AB, Harboe E, Gøransson LG, et al. Migraine is frequent in patients with systemic lupus erythematosus: a case-control study. Cephalalgia 2011;31:401-8.

20 Krokstad S, Langhammer A, Hveem K, et al. Cohort profile: the HUNT study, Norway. Int J Epidemiol 2013;42:968-77.

21 The Norwegian Institute of Public Health. Medical birth registry of Norway. Available: https://www.fhi.no/en/hn/health-registries/ medical-birth-registry-of-norway/ [Accessed 22 Feb 2020].

22 Skulstad SM, Igland J, Johannessen A, et al. Validation of materna reported pregnancy and birth characteristics against the medical birth registry of Norway. PLoS One 2017;12:e0181794.

23 Headache Classification Subcommittee of the International Headache Society. The International classification of headache disorders: 2nd edition. Cephalalgia 2004;24 Suppl 1:9-160.

24 Hagen K, Zwart JA, Vatten L, et al. Head-HUNT: validity and reliability of a headache questionnaire in a large population-based study in Norway. Cephalalgia 2000;20:244-51.

25 Hagen K, Zwart JA, Aamodt AH, et al. The validity of questionnairebased diagnoses: the third Nord-Trøndelag health study 2006-2008. $J$ Headache Pain 2010;11:67-73.

26 Skjaerven R, Gjessing HK, Bakketeig LS. Birthweight by gestational age in Norway. Acta Obstet Gynecol Scand 2000;79:440-9.

27 Børte S, Winsvold BS, Stensland Synne Øien, et al. The effect of foetal growth restriction on the development of migraine and tension-type headache in adulthood. The HUNT study. PLoS One 2017;12:e0175908.
28 Nurkhametova D, Kudryavtsev I, Khayrutdinova O, et al. Purinergic profiling of regulatory T-cells in patients with episodic migraine. Front Cell Neurosci 2018;12:326.

29 Arumugam M, Parthasarathy V. Reduction of CD4(+)CD25(+) regulatory T-cells in migraine: Is migraine an autoimmune disorder? $J$ Neuroimmunol 2016;290:54-9.

30 Andreou AP, Edvinsson L. Mechanisms of migraine as a chronic evolutive condition. J Headache Pain 2019;20:117.

31 Nielsen NM, Bager P, Stenager E, et al. Cesarean section and offspring's risk of multiple sclerosis: a Danish nationwide cohort study. Mult Scler 2013;19:1473-7.

32 Clausen TD, Bergholt T, Eriksson F, et al. Prelabor cesarean section and risk of childhood type 1 diabetes: a nationwide register-based cohort study. Epidemiology 2016;27:547-55.

33 Kristensen K, Henriksen L. Cesarean section and disease associated with immune function. J Allergy Clin Immunol 2016;137:587-90.

34 Koletzko S, Lee H-S, Beyerlein A, et al. Cesarean section on the risk of celiac disease in the offspring: the Teddy study. J Pediatr Gastroenterol Nutr 2018;66:417-24.

35 Krogh A-B, Larsson B, Linde M. Prevalence and disability of headache among Norwegian adolescents: a cross-sectional schoolbased study. Cephalalgia 2015;35:1181-91.

36 Wang S-J, Fuh J-L, Juang K-D, et al. Rising prevalence of migraine in Taiwanese adolescents aged 13-15 years. Cephalalgia 2005;25:433-8.

37 Headache classification Committee of the International headache Society (IHS) the International classification of headache disorders, 3rd edition. Cephalalgia 2018;38:1-211.

38 Børte S, Zwart J-A, Stensland Synne Øien, et al. Parental migraine in relation to migraine in offspring: family linkage analyses from the HUNT study. Cephalalgia 2019;39:854-62.

39 Wallwiener S, Goetz M, Lanfer A, et al. Epidemiology of mental disorders during pregnancy and link to birth outcome: a largescale retrospective observational database study including 38,000 pregnancies. Arch Gynecol Obstet 2019;299:755-63.

40 Minen MT, Begasse De Dhaem O, Kroon Van Diest A, et al. Migraine and its psychiatric comorbidities. J Neurol Neurosurg Psychiatry 2016;87:741-9.

41 Hagen K, Åsberg AN, Stovner L, et al. Lifestyle factors and risk of migraine and tension-type headache. follow-up data from the NordTrøndelag health surveys 1995-1997 and 2006-2008. Cephalalgia 2018;38:1919-26. 